\title{
Main Characteristics and Preventive Measures of Dust Explosion
}

\author{
Zhengyang An \\ Training department Kunming Fire Service Training School Kunming, China \\ anzhengyang2005@sina.com
}

Keywords: Dust; Explosion; Risk; Preventive measure; Main characteristics

\begin{abstract}
In recent years, due to the increasing demand for dust, the risk of dust explosion is greatly increased. Dust explosion caused a large number of casualties and huge economic losses. This paper mainly introduces the conditions, main characteristics and influencing factors of dust explosion, and puts forward the corresponding effective preventive measures.
\end{abstract}

\section{Introduction}

Combustible dust is present in places of coal mine, flour mill, sugar refinery, textile mill and the sulfur plant, feed processing plant, plastic processing factory, metal powder processing plant and grain warehouse. If these places are lack of management and control, risk of dust explosion exists. In addition, with the world's increase demand for powder products, the risk of dust explosion is also greatly increased, which is evident that a series of dust explosion accidents occurred in the major industrial countries in recent decades. In particular, in the serious dust explosion accident of Harbin Linen Textile Factory happened on March 15 of 1987, 56 people were killed and 179 people were injured. Therefore, enough attention should be paid to the problem of dust explosion.

\section{Condition of Dust Explosion}

Combustible dust explosion should generally have the following three aspects of conditions.

Dust Itself to Be Explosive. Under general conditions, not all combustible dust explosion can occur. Due to the sharp reaction and the release of huge heat in its combustion process, metal dust has an explosiveness for the rapid temperature rising and expansion of air. Therefore, it is the key to determine whether the combustible gas is released from the combustible gas. Dusts of coal, coke, graphite, charcoal, carbon black have no volatile content, so they have less possibility of explosion.

Suspended Dust Reaching the Concentration Limit of Dust Explosion. In general, the deposited combustible dust is not explosive. Only the combustible dust suspended in the air can explode. Moreover, the concentration of the suspended dust must be in the limit range of the explosion concentration to explode.

The lower limit of the combustible dust explosion concentration generally forms in the equipment or near the source, but it also does not rule out the possibility of the formation in the plant of the production. As for the upper limit of the explosion concentration, the value is so large that in most cases it will not reach, without any practical significance. For example, the explosion upper limit of powdered sugar is $13500 \mathrm{~g} / \mathrm{m}^{3}$. It is difficult to achieve this value under general conditions. Only dust deposition affected by the shock waves can form a high concentration of suspended dust. Therefore, for the explosion limit of combustible dust, only the lower limit of the concentration of the explosion is given usually.

Enough Ignition Energy. For the occurrence of the combustible dust explosion, it is required often of heating, melting evaporation, or thermal decomposition of dust to release combustible gas. The process is more complex than the combustion of the combustible gas with a longer ignition induction period up to tens of seconds. Therefore, the explosion of combustible dust requires more energy, whose minimum ignition energy is generally $10 \mathrm{~mJ}-100 \mathrm{~mJ}$, and $10^{2}-10^{3}$ times greater than that of the combustible gas. 


\section{Main Characteristics of Dust Explosion}

Compared with the explosion of combustible gas, the condition of dust explosion is relatively difficult, but the dust explosion has exactly the same characteristics of the combustible gas explosion, which are mainly embodied as follows.

Longer Action Time of High Pressure and Stronger Damage. Compared with the explosion of combustible gas, both the combustion speed and the maximum explosion pressure produced by the combustible dust explosion are slightly smaller., Due to the bigger dust density than gas, and slower rising velocity and falling speeds of explosion pressure during a longer burning time, the product of pressure and time (i.e. the energy released by the explosion) is relatively large. Combing the flying of dust particles while burning, the damage degree of the explosion to the around combustible materials is more serious. Energy generated by the dust explosion is compared with the maximum value, which is several times of that by the gas explosion, and the temperature can reach $2000 \sim 3000{ }^{\circ} \mathrm{C}$.

Formation of Secondary Explosion with more Damage. The blast of initial explosion of combustible dust can raise the dust deposition quickly which will suspend in the new space again and reach explosive concentration to produce secondary explosions. In addition, in the initial location of dust explosion, the density of the air and combustion products experiencing thermal expansion reduce, which forms a zone of negative pressure in a very short time. The fresh air flows to the point of explosion against the current, prompting secondary impact of air. When dust and fire still exist at the site of the explosion, secondary explosions and multiple explosions may occur. The secondary explosion often has greater explosion pressure and more serious damage than the initial explosion.

More Toxic Combustion Product of Dust Explosion. Due to the short time of the combustible dust explosion and the incomplete combustion of dust particles, some deposited dust may smolder. Therefore, explosion products contain a large number of $\mathrm{CO}$ and the substances of $\mathrm{HCl}, \mathrm{HCN}$ and other toxic substances generated by decomposition, which are more toxic and easy to poisoning.

\section{Influencing Factors of Dust Explosion}

(Internal Factors) Particle Size. Particle size is an important factor in the explosion of combustible dust. The smaller is the particle size, the greater is the degree of dispersion, the greater is the surface area, the stronger is the chemical activity, the longer is the time of suspension in air, and the faster is the oxidation reaction rate.

If the particle size of the dust is too large, it will not explode. For example, dusts of polyethylene, flour and methyl cellulose with particle diameter greater than $40 \mu \mathrm{m}$ will not explode, while coal dust with particle size less than $100 \mu \mathrm{m}$ will explode.

Table I list the relationship between the maximum explosion pressure and particle size.

Table I Effect of particle size of powder on explosion pressure

\begin{tabular}{l|l|l|l|l|l|l}
\hline \multirow{2}{*}{ Powder } & \multicolumn{6}{|l}{ Pressure $\left(\times 10^{5} \mathrm{~Pa}\right)$} \\
\cline { 2 - 7 } & $\begin{array}{l}20 \mu \\
\mathrm{m}\end{array}$ & $\begin{array}{l}25 \mu \\
\mathrm{m}\end{array}$ & $30 \mu \mathrm{m}$ & $40 \mu \mathrm{m}$ & $50 \mu \mathrm{m}$ & $60 \mu \mathrm{m}$ \\
\hline Wood & $\begin{array}{l}1.26 \\
\text { Wotato }\end{array}$ & - & 1.25 & - & 1.07 & 0.70 \\
$\begin{array}{l}\text { starch } \\
\text { Coal }\end{array}$ & 1.0 & - & 0.96 & - & 0.88 & 0.76 \\
$\begin{array}{l}\text { Wheat } \\
\text { flour }\end{array}$ & - & - & 0.86 & - & 0.71 & 0.27 \\
\hline
\end{tabular}

Combustion Heat. Combustible dust with high combustion heat has small lower explosion 
concentration limit. In case of explosion, the power of explosion is great because of high temperature and pressure.

Volatile Components. The more combustible volatile components the dust has, the lower is the pyrolysis temperature, and the greater are the risk of explosion and the pressure caused by the explosion. Generally, when volatile component in the coal dust is less than $10 \%$, there is basically no risk of explosion.

Ash and Water Contents. The explosion risk of the combustible dust is decreased by the increase of the ash content and water content. Because, on the one hand, they can absorb more heat from the system, thereby weakening the explosion performance of the dust. On the other hand, ash and water will increase the density of the dust, accelerate the sedimentation rate, and reduce the concentration of suspended dust. Experimental results show that there will be no explosion when the ash content in the coal dust is up to $30 \% \sim 40 \%$.

(External Factors) Oxygen Content. Dust explosion is sensitive to oxygen content, since the explosion concentration range is extended with the increase of oxygen content in the air. The dust explosion concentration limit in the pure oxygen is down to only one third to a quarter of that in the air, and the maximum particle size of the explosion can increase by 5 times of that in the air.

Air Humidity. The dust explosion risk decreases with the increase of air humidity. Because it is conducive to the elimination of dust electrostatic and the acceleration of dust condensation by the increase of the humidity. At the same time, the evaporation of water can consume the thermal energy of the system, dilute the oxygen content in the air, and reduce the burning reaction rate of dust, so it is not easy for the dust to explode.

Combustible Gas Content. When the dust and the combustible gas coexist, the lower limit of the dust explosion concentration is decreased correspondingly, and the minimum ignition energy is reduced to a certain extent, which means that the combustible gas can greatly increase the risk of dust explosion. Figure 5 shows the effect of the methane content to the lower limit of the coal dust explosion concentration.

Temperature and Pressure. When temperature or pressure increases, the dust explosion concentration range will be expanded, while the energy required to light energy is reduced, leading to the increase of the explosion risk.

Intensity of Fire Source and Minimum Ignition Energy. The higher is the temperature and the greater is the intensity of the fire source, and the longer is the contact time with the dust mixture, the more wide range the explosion will have, and the greater the risk of explosion will be.

For each kind of combustible dust, there is a minimum ignition energy under certain conditions. If the energy is less than that value, the mixture of dust and air will not explode. The smaller is the dust ignition energy, the greater the risk of explosion will be.

\section{Prevention of Dust Explosion}

The corresponding preventive measures in the fire protection work can be taken after mastering the harm of dust explosion and its influencing factors. According to the practice, measures usually taken are as follows:

Control of the Dust Concentration in Air. Equipment with good sealing performance should be applied to minimize flying escape of the dust. Effective ventilation and dust removal equipment should be installed, the cleaning work should be strengthened, and dust in the motors, lamps, ditches and on the walls should be removed timely.

Control of Indoor Humidity. Dust explosion usually occurs indoors or in the container. When the relative humidity in the room or container is more than $65 \%$, the dust flying can be reduced and the static electricity can be eliminated, thus explosion can be avoided.

Improvement of the Equipment and Control of the Fire Source. All hazardous locations of dust explosion are belong to G1 grade. Therefore, explosion-proof motors, explosion-proof lights, explosion-proof switches and other explosion-proof electrical equipment should be equipped. Open fire operation, smoking and wearing shoes with nails are forbidden.

Control of Temperature and Oxygen Concentration. It is necessary to frequently measure the 
temperature of machine to prevent frictional heat., Cooling measures should be taken on every container with dust deposit. When necessary, inert gases (such as $\mathrm{N}_{2}$ ) can be filled to dilute oxygen content.

Prevention of the Secondary Explosion. In the fighting of dust fire, attention should be paid to prevent the dust deposit from flying up. The fire extinguishing agent with impact force like $\mathrm{CO}_{2}$ should not be used. It would be the best to use spray water flow to prevent the secondary explosion.

\section{Conclusion}

Chemical explosion accidents of combustible gas are relatively common and it is easy to arouse people's attention, while the risk and harm of combustible dust explosion is often neglected due to its required larger explosion concentration and ignition energy, which is easy to breed people's careless psychology and eventually results in the scene of the tragedy. Therefore, we must effectively improve the awareness of the risk and harm of dust explosion, establish safety production system according with the standard, strictly abide safety production system in the production process, and improve the prevention and disposal capacity of dust explosion.

\section{References}

[1] Fire Department of the Ministry of public security. Special service training [M]. Shanghai: Wenhui Press, 2001, March

[2] Chen Jiaqiang. Discussion on rescue of chemical disaster accident[Z],Chinese Fire, 1998(4-5)

[3] He Liqiu. Fire combustion science [M]. Yunnan: Yunnan People's Publishing House,2006, May

[4] Zhang Guanghua. Safety technology and management of hazardous chemicals production [M]. Beijing: China Petrochemical Press, 2004

[5] Yang Lihong. Measures and Countermeasures to strengthen the management of pesticide [J].Pesticide science and management, 2012, 33(4): 7-9.

[6] Chen Meibao, Wang Wenhe. Basic knowledge of hazardous chemical safety. Beijing. China Labour \& Social Security Publishing House, 2010.

[7] Fire Department of the Ministry of public security of the people's Republic of China. China Fire Manual: The seventh volume of hazardous chemicals, special agents and dust[M].Shanghai: Shanghai Science and Technology Press, 2006.

[8] Tang Chaogang. Fundamental safety management of hazardous chemicals[M].Beijing: China Machine Press, 2014.

[9] Zhao Qingxian, Shao Hui, Ge Xiukun. Safety management of hazardous chemicals [M]. Beijing. China Petrochemical Press, 2010.

[10] Su Hualong. Safety management of hazardous chemicals [M]. Beijing. Chemical Industry Press, 2006. 